\title{
INVESTIGATION OF WAVE INDUCED STORM SURGE WITHIN A LARGE COASTAL EMBAYMENT - MORETON BAY (AUSTRALIA)
}

\author{
Philip Treloar ${ }^{1}$, David Taylor ${ }^{2}$ and Paul Prenzler ${ }^{3}$
}

\begin{abstract}
Moreton Bay is a large coastal embayment on the south-east Queensland coast which is surrounded by the urbanised areas of greater Brisbane on its western and southern shorelines. It is protected from the open coast by a number of islands, including South Stradbroke, North Stradbroke and Moreton Islands. Tropical cyclones occasionally track far enough south to cause significant damage to south-east Queensland due to flooding, winds, waves and elevated ocean water levels. Distant tropical cyclones which may be several hundred kilometres north of Moreton Bay have been known to cause storm surge, high waves and erosion inside Moreton Bay. These events generally do not generate gale force winds within Moreton Bay, but can generate large ocean swell waves. It has been identified that the wave conditions generated from distant cyclones can cause a variation in water levels inside Moreton Bay. A detailed study was undertaken to investigate the regional wave set-up process which affects Moreton Bay. The simulation of the residual water levels within Moreton Bay using a coupled hydrodynamic and wave model system developed for this study is considerably more accurate than applying a hydrodynamic model alone and explains water level anomalies that have a tidal frequency. The paper discusses the physical process of regional wave set-up inside a large embayment, analysis of observed residual water level and also the modelling study undertaken to quantify the influence of waves on storm tide levels inside Moreton Bay. The storm tide hazard study for the Moreton Bay Councils included the effects of regional wave set-up in the specification of design water levels.
\end{abstract}

Keywords: Moreton Bay, regional wave set-up, storm tide

\section{INTRODUCTION}

Wave set-up is a process commonly observed on open coast beaches where the mean water level increases between the zone of wave breaking and the shoreline. It is caused by the conservation of momentum flux during wave breaking. In simple terms, wave set-up can be viewed as the conversion of some of the kinetic energy released during wave breaking into potential energy in the form of a rise in the mean water level surface.

Whilst wave set-up is usually associated with open coast beaches, studies have also shown that wave set-up can influence water levels within estuarine entrance and coastal embayment systems. Wave breaking at the entrance to a coastal embayment can cause a rise in the mean water level, the rise depending upon embayment size and depth, other waterways and storm parameters, such as duration. This process has been documented in numerous studies that have applied data analysis and numerical modelling techniques. Tanaka and Puzari (1993), Tanaka et al (2000) and Nguyen et al (2007) have investigated the impact of wave set-up on measured water levels inside river and inlet entrances on the coast of Japan. Those studies suggest that entrance morphology is important in determining how wave set-up will influence water levels inside the entrances. Those investigations indicated that wave set-up, or wave momentum flux processes in breaking wave conditions, could increase water levels inside entrances by $10 \%$ to $15 \%$ of the offshore wave height for shallow and narrow entrances, and $0.2 \%$ to $4 \%$ of the offshore wave height for deep and wide entrances.

The influence of wave set-up on residual water levels inside Moreton Bay is described in the following sections. For this study, a combined wind, hydrodynamic and wave model system was developed to investigate storm tide and wave related storm surge inside Moreton Bay. The Delft3D hydrodynamic model and SWAN wave model have been adopted for numerous similar studies worldwide. The calibrated model was applied to increase the understanding of wave interaction with water levels inside Moreton Bay and then also to include regional wave set-up in the calculation of design water levels for Local Government Areas (LGAs) around the shoreline of Moreton Bay. Shoreline wave set-up was calculated also.

\section{STUDY AREA}

Moreton Bay is a large coastal embayment on the south-east Queensland coast. It is separated from the Tasman Sea by a series of islands including South Stradbroke, North Stradbroke and Moreton Islands. The western side of Moreton Bay is surrounded by the urbanised areas of greater Brisbane on

\footnotetext{
${ }_{1}^{1}$ Cardno Lawson Treloar, 910 Pacific Highway, Gordon, NSW, 2072, Australia

${ }^{2}$ Cardno Lawson Treloar, 2 Bagot Road, Subiaco, WA, 6008, Australia

${ }^{3}$ Department of Environment \& Resource Management, 400 George Street, Brisbane, QLD, 4000, Australia
} 
its western and southern shorelines. To the south, Moreton Bay connects to the Broadwater system of the Gold Coast. Figure 1 presents a plan view, including bathymetry, of Moreton Bay.

There are a number of entrances connecting the Tasman Sea and Moreton Bay. The most significant of these is the large entrance between Moreton Island and Bribie Island in the north-west corner of Moreton Bay. This entrance features a large sand shoal area that is generally only 5 to $6 \mathrm{~m}$ deep along a $25 \mathrm{~km}$ section known as Spitfire Banks - see Figure 1.

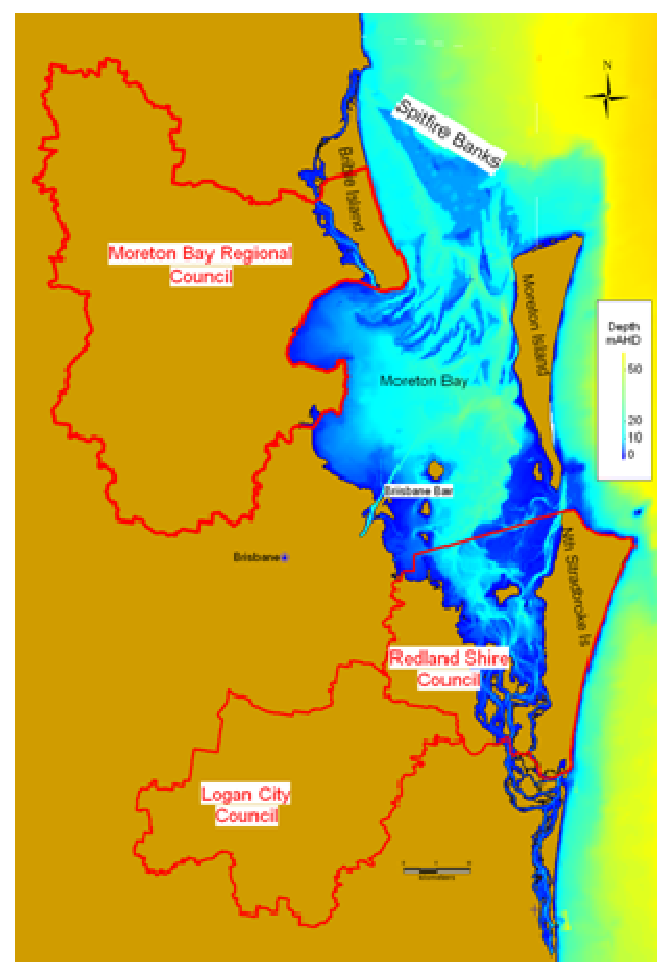

Figure 1. Detailed Plan View of the Study Area Including Bathymetry

The study area is located near the southern limit of tropical cyclone activity for east coast Australia under current climatic conditions. South of Gladstone $(500 \mathrm{~km}$ north of Moreton Bay) on the Queensland coast, the frequency and intensity of tropical cyclones diminishes rapidly. Storm surges in the Moreton Bay region are more likely to be generated by decaying tropical cyclones, transitioning extra-tropical storms, sub-tropical storms or "east coast lows" (ECL). However, extreme storm tide events, for example at the 100-years Average Recurrence Interval (ARI) or greater, are likely to be the result of tropical cyclones which are able to track as far south as Moreton Bay. Cardno Lawson Treloar (2009a and 2009b) present a detailed description of the storm climatology for the Moreton Bay region.

Cardno Lawson Treloar were commissioned in 2007 by Moreton Bay Regional Council, together with Redland and Logan City Council's, to undertake a comprehensive storm tide study for these Local Government Areas (LGA's). The purpose of that study was to enable a standardised best practice, regional approach to be established with regard to storm tide modelling, mapping, risk assessments and mitigation strategies. The full description of the storm tide study including outcomes is presented in Cardno Lawson Treloar (2009a, 2009b, 2009c and 2009d).

A key component of the storm tide study was to develop and calibrate a coupled, wave and hydrodynamic model system which would be the basis of the storm tide study. During the setup and calibration process, the interaction of wave and hydrodynamic processes, in particular water levels, was a key component.

\section{MODEL DESCRIPTION}

The model system developed for this study included the Delft3D hydrodynamic model coupled with the SWAN wave model system. The Delft3D model system is developed and maintained by Deltares (formally Delft Hydraulics). The SWAN wave model has been developed by the Delft Technical University and is the wave model adopted in the Delft3D model system. 
These two model systems have been validated in numerous hydrodynamic modelling studies around Australia and many other locations. The coupling of the SWAN wave model with the Delft3D hydrodynamic model has been demonstrated to be an appropriate technique for simulation of water levels and currents inside coastal entrance systems, including the Murray River Mouth and Coorong (Treloar and Patterson, 2004) and Lake Illawarra (Taylor et al 2008). The Delft3D model system has also been applied in the simulation of coastal and inlet storm water levels in overseas studies, for example, the simulation of storm water level near Long Island, which highlighted the importance of wave induced radiation stresses in simulating water levels inside a barrier island system (Irish et al, 2004).

A full description of the Delft3D and SWAN models developed for this study is presented in Cardno Lawson Treloar (2009a and 2009b). The models included a variable resolution, multi-domain configuration. The SWAN model extended northward and eastward over $2,000 \mathrm{~km}$ from the origin. The large model extent was required to enable realistic simulation of waves generated from gradient winds across the Tasman Sea, as well as describing the rotating wind fields of cyclones.

Wind fields for the wave and hydrodynamic models were generated using a modified Holland (1980) parametric cyclone wind model with forward windfield asymmetry for cyclone events, and a blended satellite wind dataset available from the National Oceanic and Atmospheric Administration (NOAA) for non-cyclonic storm events (Zhang et al, 2006).

\section{MODEL CALIBRATION}

The wind, wave and hydrodynamic models adopted in the Moreton Bay storm tide study were all calibrated for a series of historical storm events. Calibration of the hydrodynamic model also included a calm winds tidal case in order to prepare a bed friction map. Quantitative analysis of modelled tides was undertaken at a total of seven sites within the model domain. Predicted tides for comparison to the modelled water levels were generated using the Foreman (1977) method. Tidal constants were obtained from the published tide constants (Australian Hydrographic Office, 2007). The calibration of the hydrodynamic model for tidal flows and the wind and wave models is presented in Cardno Lawson Treloar (2009a and 2009b). Offshore tidal constants were obtained from the Oregon State University global model of ocean tides which was along-track averaged data from the TOPEX/Poseidon and Jason (on TOPEX/Poseidon tracks since 2002) satellite altimeter data. The methodology of the global tidal models is described in Egbert and Erofeeva (2002).

The calibration of the model systems for storm surge consisted of the hindcast simulations of four historical events. The calibration of the model system to these events is described in the following sections.

\section{TROPICAL CYCLONE DINAH (TC DINAH)}

TC Dinah was one of the most damaging storms to have affected the south-east Queensland coast in the last 50-years. The peak storm surge persisted for nearly 24-hours, which coincided with a spring tide high water. The peak measured storm surge at the Brisbane Bar tide gauge was $0.45 \mathrm{~m}$. TC Dinah generated severe offshore wave conditions which were predominantly from the east to south-east sector (significant wave height $-\mathrm{H}_{\mathrm{s}} \approx 9 \mathrm{~m}$ ). The hindcast of TC Dinah was undertaken with the Delft3D hydrodynamic model, including wind and atmospheric pressure forcing on its own, as well as coupling with the SWAN wave model. Whilst the coupled wave and hydrodynamic model improved the calibration of the model compared to the measured storm surge, the influence of wave processes on the measured storm surge was small, less than $0.1 \mathrm{~m}$. Figure 2 presents a time series comparison of modelled (including wave, wind and pressure forcing) and measured storm tide at Brisbane Bar during TC Dinah. 


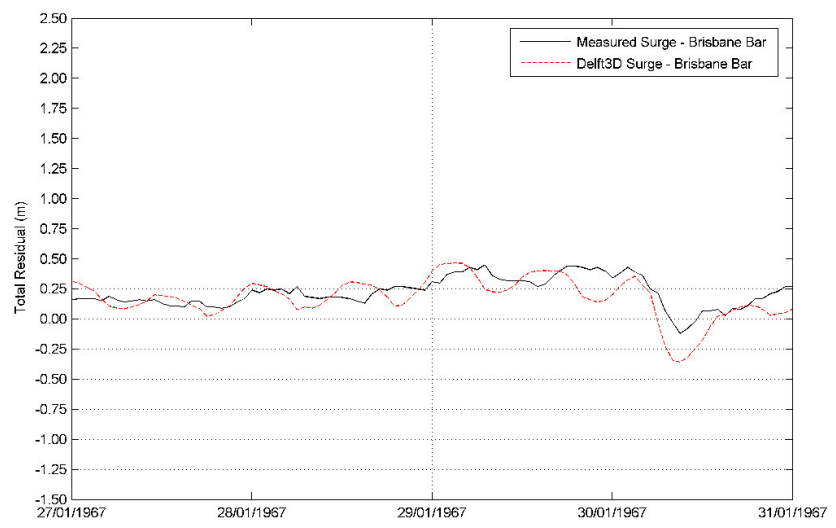

Figure 2. Comparison of modelled residual water level (dashed red line) and measured tide (solid black line) at Brisbane Bar tide gauge during TC Dinah

\section{TROPICAL CYCLONE DAISY (TC DAISY)}

TC Daisy was another relatively intense tropical cyclone for south-east Queensland that tracked much closer to Moreton Bay compared to TC Dinah. The peak measured storm surge at Brisbane Bar was about $0.7 \mathrm{~m}$ and occurred near mid-tide in a transitional tide period (between spring and neap). Compared to TC Dinah, the peak storm surge was of much shorter duration. The peak total water level of TC Daisy was approximately $0.2 \mathrm{~m}$ lower inside Moreton Bay compared to TC Dinah. This storm generated severe offshore wave conditions $\left(\mathrm{H}_{\mathrm{s}}=7 \mathrm{~m}\right)$, predominantly from the north-east direction offshore. This direction corresponds with the alignment of the northern entrance to Moreton Bay.

Figure 3 presents time series of measured residual water level, modelled total residual water level, modelled residual water level due to wind and pressure forcing, and residual water level due to the wave forcing. The agreement between modelled residual water level with wind, pressure and wave forcing and the measured residual water level is significantly improved compared to the modelled case with wind and pressure forcing only. The modelled storm surge peaks approximately 3-hours before the measured surge; however, the cyclone track data available for this event had a time step of 6-hours. The residual water level in Figure 3 generated by the wave forcing shows a distinct periodic character which corresponds to the semi-diurnal tide frequency. This outcome indicates that the regional wave set-up within Moreton Bay is strongly linked to the astronomical tide.

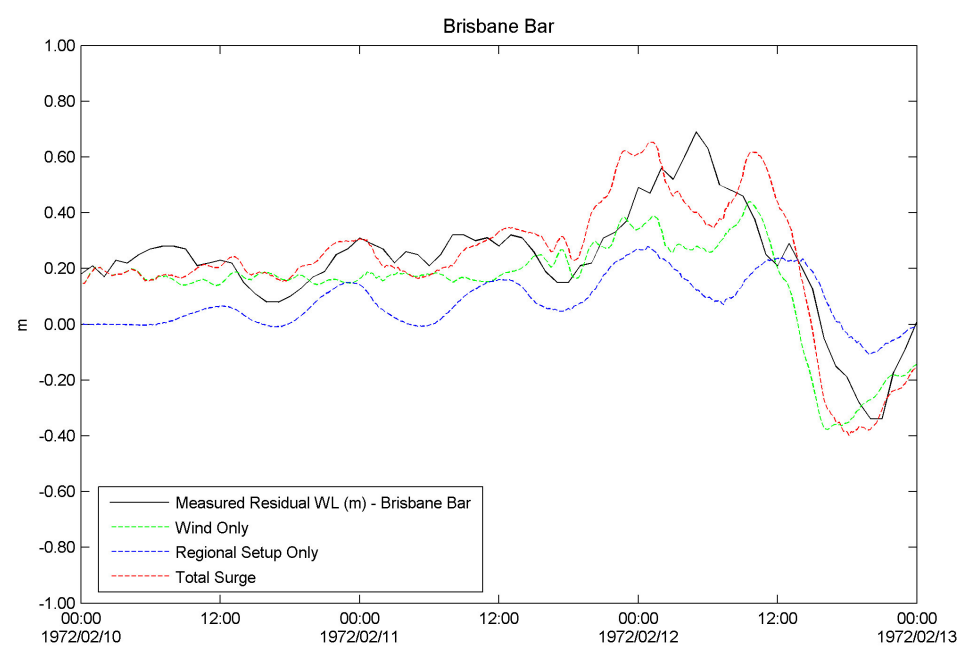

Figure 3. Comparison of measured residual water level (solid black line) with the modelled residual water level (dashed red line) at Brisbane Bar during TC Daisy. The modeled residual result has also been separated into the wind and pressure only component (dashed green line) and also the regional wave set-up component (dashed blue line). 
Figure 3 presents time series of measured residual water level, modelled total residual water level, modelled residual water level due to wind and pressure forcing, and residual water level due to the wave forcing. The agreement between modelled residual water level with wind, pressure and wave forcing and the measured residual water level is significantly improved compared to the modelled case with wind and pressure forcing only. The modelled storm surge peaks approximately 3-hours before the measured surge; however, the cyclone track data available for this event had a time-step of 6-hours. The residual water level in Figure 3 generated by the wave forcing shows a distinct periodic character which corresponds to the semi-diurnal tide frequency. This outcome indicates that the regional wave set-up within Moreton Bay is strongly linked to the astronomical tide

Over the three-day period presented in Figure 3, the correlation coefficient between modelled and measured storm surge (including wind, pressure and wave forcing) was 0.87 . This indicates very good temporal agreement between modelled and measured residual water level and suggests that the wave component of the measured residual water level is also related to the astronomical tide.

\section{MARCH 2004 TROPICAL LOW EVENT}

In March 2004 a tropical low system developed off the central Queensland coast. Since this event is more recent than the previous two model calibration events, there was additional model calibration data and higher resolution and more accurate wind and pressure data with which to force the wave and hydrodynamic models. High-resolution blended satellite wind data available from NOAA was found to agree very well with measured 'over-water' wind conditions observed at sites within Moreton Bay (Cardno Lawson Treloar 2009a and 2009b). This storm event generated the highest recorded storm surge $(0.73 \mathrm{~m})$ at the Brisbane Bar tide gauge since its inception in 1967 . The peak storm surge coincided with low water. The event generated offshore waves up to $7 \mathrm{~m}\left(\mathrm{H}_{\mathrm{s}}\right)$ from the north-east to east sector.

Figure 4 presents time series of measured residual water level (solid black line), modelled total residual water level, modelled residual water level due to wind and pressure forcing, and residual water level due to the wave forcing. As with TC Daisy, the wave induced residual water level is significant and accounts for approximately $30 \%$ of the peak modelled storm surge.

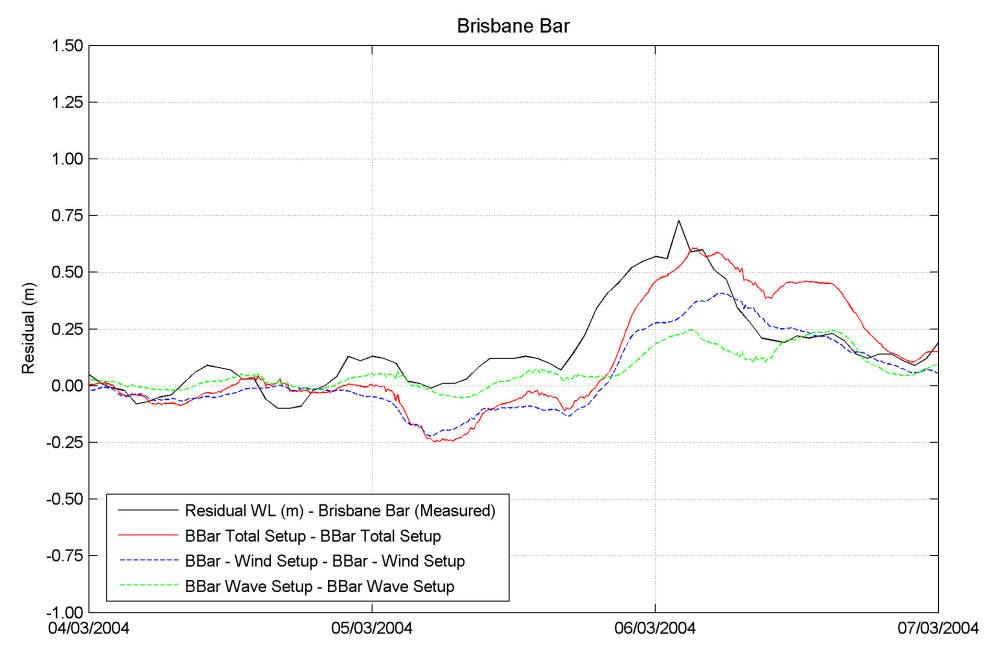

Figure 4. Comparison of measured residual water level (solid black line) with the modelled residual water level (solid red line) at Brisbane Bar during the March 2004 Tropical Low event. The modeled residual result has also been separated into the wind and pressure only component (dashed green line) and also the regional wave set-up component (dashed blue line).

Spectral analyses were also undertaken on the modeled and measured residual water level from the March 2004 event. A Fast Fourier Transfer (FFT) analysis was undertaken on a 128-hour duration, 1hourly record of the measured and modeled water levels. Figure 5 presents a comparison of the water level spectra (Power Spectral Density function). The Y-axis of Figure 5 is presented as period of oscillation (1/frequency) rather than frequency itself. The modeled residual water level spectra with wave forcing (dashed red line) is a good representation of the measured spectra (solid blue line) with both these cases indicating a peak residual water tide period of oscillation near 12.5 hours which is 
consistent with the semi-diurnal astronomical tide cycle at the site. The modeled residual water level spectra without wave forcing (dot-dashed green line) does not agree with the measured water level spectra for the period range greater than 9-hours.

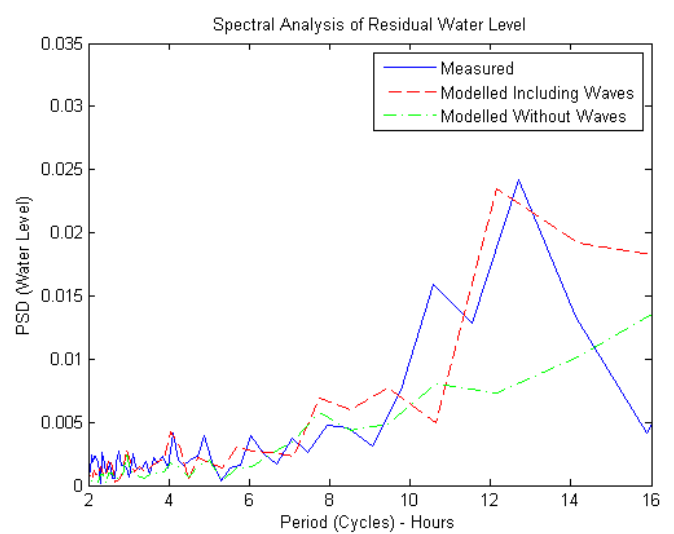

Figure 5. Comparison of measured residual water level spectra (solid blue line), modeled water level spectra with wave forcing (dashed red line) and modeled water level spectra without wave forcing (dot-dash green line).

\section{JULY 2001 TASMAN SEA LOW EVENT}

A moderate wave event was observed on the 6th and 7th July, 2001. The waves were generated by an intense low in the Tasman Sea, some $1,500 \mathrm{~km}$ to 2,000km east of Brisbane. Offshore wave heights reached $4 \mathrm{~m}\left(\mathrm{H}_{\mathrm{s}}\right)$ at the Brisbane Waverider buoy with peak periods (peak spectral period - $\mathrm{T}_{\mathrm{p}}$ ) of up to 12 seconds. The offshore wave direction was generally east at the peak of the event. Due to the storm being located so far away from the study area, wind conditions and atmospheric pressure during the time of the large offshore wave conditions had very little influence on water levels along the south-east Queensland coast. As a result, this event represents a period of time when only wave processes are likely to have influenced water levels inside Moreton Bay.

Observed water levels at Mooloolaba (open coast), Brisbane Bar and Southport (Broadwater, Gold Coast in the southern-most modeled area) have been analysed for this event. Generally, the residual water level is small at Mooloolaba on the open coast; less than $0.05 \mathrm{~m}$. At Brisbane Bar, the residual water level shows a clear oscillatory character with a period of oscillation of about 12 hours which is consistent with observed and modeled residual water level from TC Daisy and the March 2004 event. The magnitude of the residual water level is up to $0.19 \mathrm{~m}$ coinciding with the peak in offshore wave heights. Southport also shows some residual water level with a similar character to Brisbane Bar near the peak of the event, however, the magnitude of the residual water level was much smaller than at Brisbane Bar.

Figure 6 presents time series of measured and modeled residual water level at Brisbane Bar with wind and pressure forcing only. Figure 7 presents time series of measured and modeled residual water level at Brisbane Bar with wave, wind and pressure forcing. Compared to Figure 6, the agreement between modelled and measured water levels is significantly improved. This outcome confirms that the coupled wave and hydrodynamic model system developed for this study is able to simulate the observed residual water level due to wave processes to a good degree of accuracy.

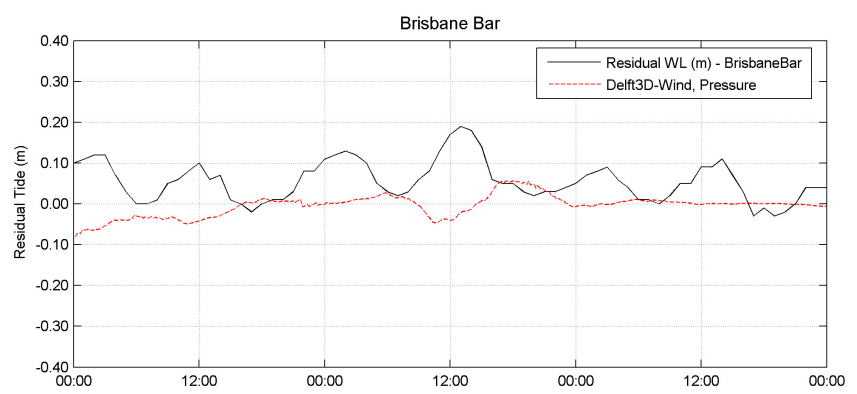

Figure 6. Comparison of measured residual water level (solid black line), and modelled residual water level with wind and pressure forcing only (dashed red line) at Brisbane Bar during the July 2001 event 


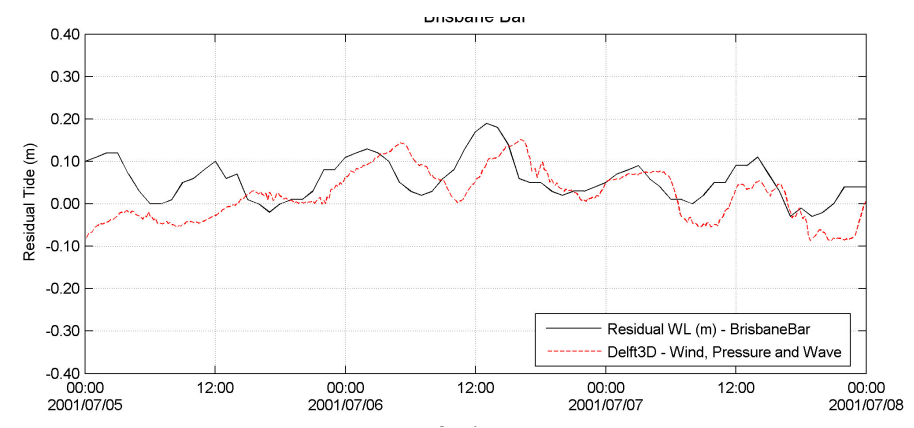

Figure 7. Comparison of measured residual water level (solid black line), and modelled residual water level with wave, wind and pressure forcing (dashed red line) at Brisbane Bar during the July 2001 event

\section{REGIONAL WAVE SET-UP INSIDE MORETON BAY INVESTIGATIONS}

Following the calibration of the coupled wind, wave and hydrodynamic models, it was evident that during particular storm events, there is a residual water level inside Moreton Bay that cannot be attributed to either inverse barometer or conventional wind set-up processes. Earlier storm tide studies of Moreton Bay, for example, Blain, Bremner and Williams (1979), had identified that waves were likely to influence storm tide inside Moreton Bay but, neither the mechanism of action nor a quantified assessment of the influence of waves on the residual water level has been undertaken before. A study was undertaken prior to the storm tide risk investigations to better understand the influence that wave breaking over Spitfire Banks was having on residual water levels inside Moreton Bay.

A series of parametric simulations was undertaken with the Delft3D model to investigate the relationship between the regional wave set-up inside Moreton Bay and offshore wave height, period and direction. Each simulation was run for a period of three days. During the first day, the wave height increased from $2 \mathrm{~m}\left(\mathrm{H}_{\mathrm{m} 0}\right)$ up to the simulation value. During the second day, the wave height remained constant at the specified value and on the third day the wave height again decreased to $2 \mathrm{~m}\left(\mathrm{H}_{\mathrm{m} 0}\right)$. Wave period and direction remained constant at the selected values during the whole simulation. Tide forcing was included in all simulations.

These simulations identified and quantified several significant features of the regional wave set-up process inside Moreton Bay. The magnitudes of the offshore wave height and wave period were positively correlated with the simulated regional wave set-up. That is, a larger regional wave set-up was observed with larger offshore wave heights and/or longer periods. The magnitude of wave set-up for north-east and easterly waves is significantly higher than for similar south-easterly waves. Southeasterly waves lose significant wave energy due to refraction before reaching Spitfire Banks.

Tidal flows also have a significant impact on the magnitude of the modelled regional wave set-up. Regional wave set-up increases on the ebb tide and peaks near low water. Near high-water, the magnitude of the regional wave set-up is significantly reduced. This outcome is, at first, counterintuitive. Figure 8 presents a plan view of regional wave set-up within Moreton Bay near high tide. During this simulation the offshore wave height was $7 \mathrm{~m}\left(\mathrm{H}_{\mathrm{m} 0}\right)$, wave period was $8 \mathrm{~s}\left(2^{\text {nd }}\right.$ spectral moment $-\mathrm{T}_{\mathrm{m} 02}$ ) and the direction was easterly. Figure 8 presents a plan view of regional wave set-up around Moreton Bay for the same offshore wave conditions near low tide. Near high water, the magnitude of the regional wave-setup within Moreton Bay, with the exception of the immediate vicinity of Spitfire Banks, is between 0.05 and $0.1 \mathrm{~m}$. Near low tide and with the same wave conditions the magnitude of the regional wave set-up within Moreton Bay is approximately $0.3 \mathrm{~m}$. 


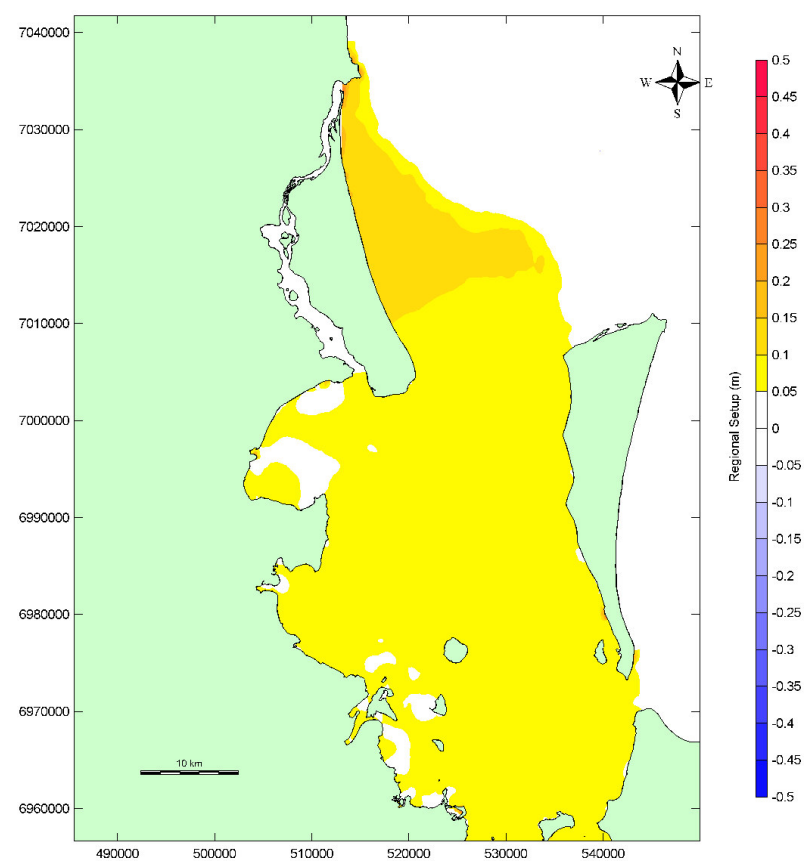

Figure 8. Plan view of modelled residual water level inside Moreton Bay due to regional wave set-up near high tide

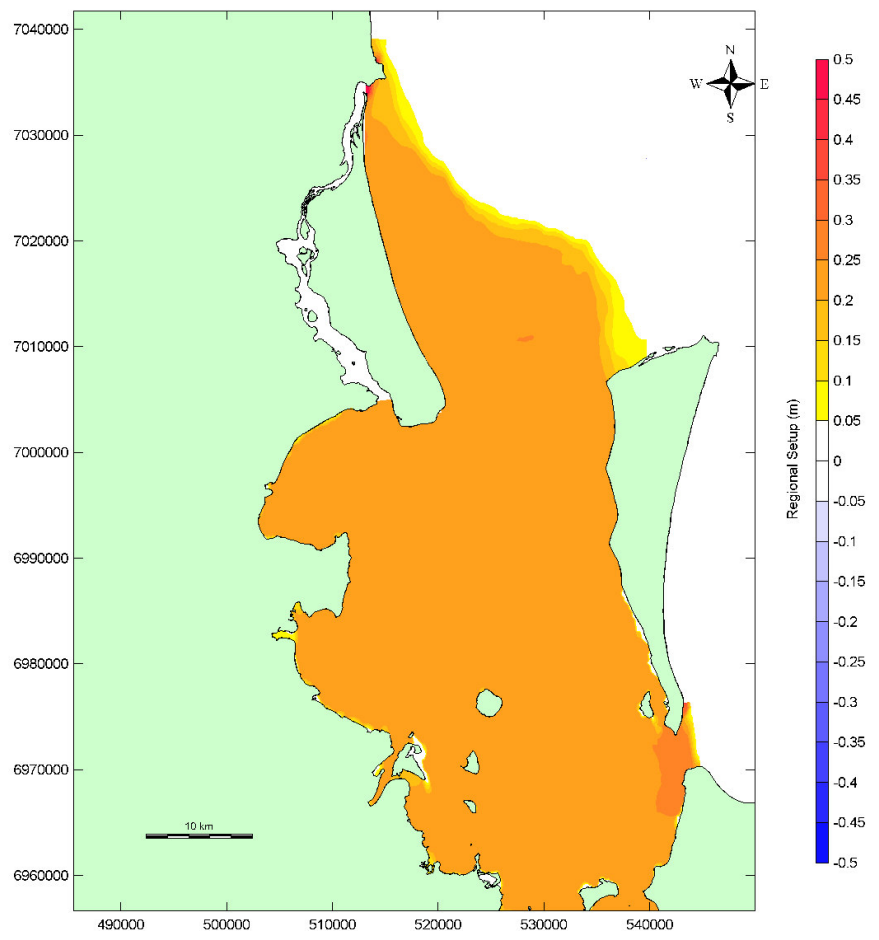

Figure 9. Plan view of modelled residual water level inside Moreton Bay due to regional wave set-up near low tide

This outcome suggests that the regional wave set-up has a momentum flux component that acts to reduce the mass flux. That is, the residual water level generated by the regional wave set-up is largely due to a gradient in radiation stresses in Moreton Bay that acts against the ebb tide flow rather than a mass influx into Moreton Bay. A mass influx is generated by the wave breaking; however, the mass influx is only a minor contributor to the residual water level generated by the wave breaking process at Spitfire Banks. 
PARAMETRIC MODEL OF REGIONAL WAVE SET-UP INSIDE MORETON BAY

The technique used to calculate design storm tide levels in the Moreton Bay storm tide study adopted a Monte Carlo procedure that simulated 6,000 cyclone events. Storm surge for each event was interpolated from a database of results from a large number of base cyclone cases simulated with the Delft3D model. The Monte Carlo model then combined the modelled storm surge during that event with a random astronomical tide to generate the total storm tide. Cardno Lawson Treloar (2009a and 2009 b) presents a complete description of the Monte Carlo modelling technique adopted in this study.

Due to the interaction between the astronomical tide and the magnitude of the regional wave set-up process, a parametric model was developed which allowed the magnitude of the regional wave set-up to be estimated for each cyclone event in the Monte Carlo model. A series of regression models have been developed based on the simulations described in the regional wave set-up description presented above. These models can be easily implemented within the Monte Carlo procedure whereby, for a modelled offshore wave height, period and direction occurring during a cyclone event, the magnitude of regional wave set-up can be determined realistically.

The regional wave set-up $(\eta)$ relationship for Moreton Bay has been developed into a simple linear regional model of the form presented in Equation 1 where the coefficients $\beta_{0}$ and $\beta_{1}$ are calculated by regression analysis of the simulations described above.

$$
\eta=\beta_{0}+\beta_{1}\left(H_{m 0} \times T_{m 02}\right)
$$

Figure 10 presents the linear regression model presented in Equation 1 for easterly waves and indicates that, for typical storm wave conditions, the linear regression model presented in Equation 1 is a very good estimate of the modelled regional wave set-up using the coupled wave and hydrodynamic model. The correlation coefficient is greater than 0.96 for all wave directions and tide levels.

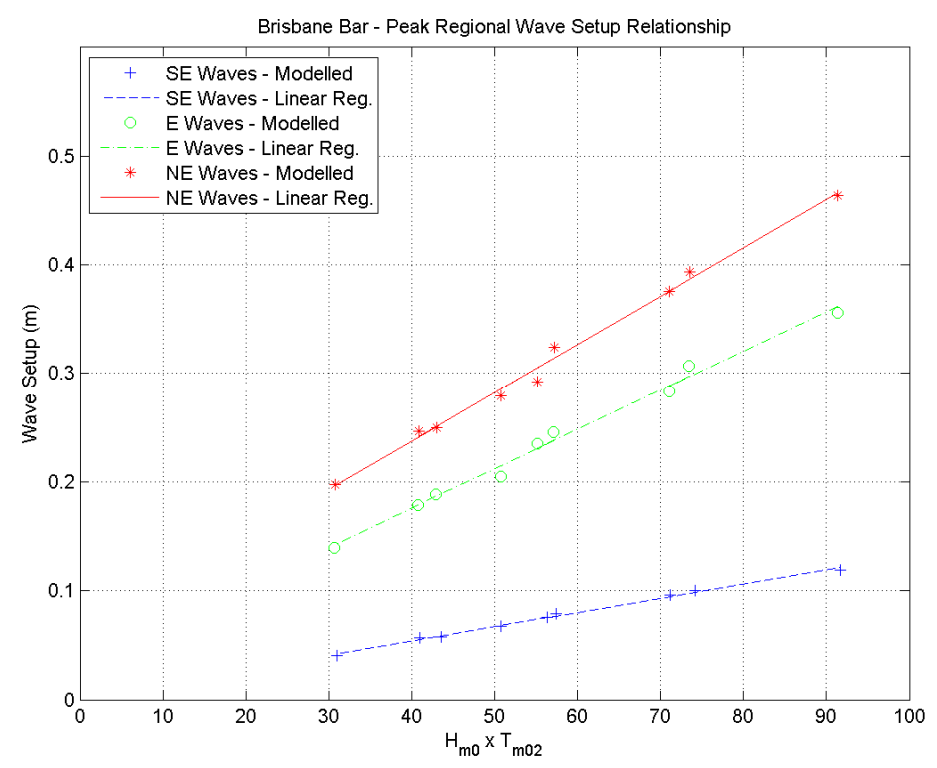

Figure 10. Parametric regional wave set-up models for southeasterly (blue), easterly (green) and northeasterly (red) offshore wave directions.

Equation 1 has been developed for the regional wave set-up occurring during the tide cycle for low and high tide. Near high water, which is typically where peak storm tide occurs, the magnitude of the regional wave set-up is generally $25 \%$ to $35 \%$ of the peak wave set-up which occurs near low water. This tidal phase reduction was included in the Monte Carlo design storm tide analyses.

\section{DISCUSSION}

The Moreton Bay study has highlighted the importance of wave breaking processes along Spitfire Banks on the observed water level inside Moreton Bay. Analysis of the long-term historical water level record from the Brisbane Bar tide gauge indicated that for certain events, the magnitude of the total 
residual water level is greater than that which could be generated by wind and atmospheric pressure forcing alone. During those events, which are typically related to distant storms, the residual water level also displays a distinct periodic character which corresponds with the semi-diurnal tide.

The coupled Delft3D hydrodynamic and SWAN wave model system developed for this study has been shown to be able to more accurately simulate the observed storm surge compared to a hydrodynamic model with wind and pressure forcing alone. Investigations of the regional wave set-up process inside Moreton Bay have identified that as well as the height and period of the offshore waves, the offshore wave direction and the astronomical tide phase both significantly influence the residual water level generated inside Moreton Bay due to wave breaking along Spitfire Banks. This study suggests that the regional wave set-up process inside Moreton Bay is largely related to a momentum flux process. That is, the residual water level generated by the regional wave set-up is largely due to a gradient in radiation stresses at Spitfire Bank in northern Moreton Bay which acts against the ebb tide flow rather than as a mass influx into Moreton Bay.

The Delft3D model also suggests that for a given event, the amount of regional wave set-up around Moreton Bay is generally uniform with spatial gradients in residual water level only evident near Spitfire Banks. Other entrances to Moreton Bay also exhibit a wave set-up effect inside the entrance, see Figure 9; however, the influences of these entrances on the hydrodynamics of the whole Bay is less important due to the geometry of these entrances.

The influence of regional wave set-up on the design water levels for the LGAs is not as great as was first expected. Due to the significant reduction in the magnitude of the residual water level caused by waves near high water (compared to low water), for the 100-years ARI storm tide the contribution of the regional wave set-up to the storm tide within Moreton Bay was approximately $0.1 \mathrm{~m}$. This is largely due to the fact that design water levels are most likely caused by more frequent and less intense storms generating peak storm surge near high tide, than less frequent, but more intense storms. Whilst the contribution of regional wave set-up to the total storm tide levels around Moreton Bay is not large, this study has highlighted the importance of including this process during the model calibration process and to improve understanding of water level residuals.

\section{CONCLUSION}

A detailed and comprehensive storm tide study was undertaken for a number of LGAs in south-east Queensland in 2008. As part of this study an investigation into the influence of wave processes on the residual water level inside Moreton Bay was undertaken.

Those investigations indicated that, for particular storm events, wave breaking near the entrance to Moreton Bay can contribute a significant amount to the total storm surge observed within Moreton Bay. This 'Regional Wave Set-up' process is most significant when waves originate from the north-east to east sector offshore, and when the astronomical tide is near low water on the ebb tide. Near high-water the influence of this regional wave set-up is generally only $25 \%$ to $35 \%$ of the magnitude near low water for constant offshore wave conditions.

The influence of wave breaking on water levels within embayments has been confirmed at a number of other sites around Australia and overseas. The geometry of the embayment and form of the entrance together with its orientation to the offshore wave direction, are key factors governing the presence and magnitude of wave set-up occurring within the embayment during a storm. The regional wave set-up observed and modelled inside Moreton Bay is specific to the Moreton Bay system and may not occur at every coastal site.

\section{ACKNOWLEDGMENTS}

This project was funded through the Working Together To Manage Emergencies - Local Grants Scheme, made available through the Australian Government Attorney-General's Department represented by Emergency Management Australia. The project was run as a joint study by funding provided to (the then) Caboolture Shire Council and Redland Shire Council on behalf of the Moreton Bay Regional Council (incorporating Caboolture Shire Council, Pine Rivers Shire Council and Redcliffe City Council), Redland City Council and Logan City Council. The authors would also like to acknowledge the contribution of the Bureau of Meteorology and the Queensland Environmental Protection Authority throughout the course of this study. The authors thank those bodies for their permission to publish this paper. 


\section{REFERENCES}

Australian Hydrographic Office (2007) 2008 Australian Tide Tables

Published by the Australian Hydrographic Office, Government of Australia.

Blain, Bremner and Williams Pty Ltd (1979 April) New Brisbane Airport. Historical Study of Storm Tides in Moreton Bay.

Report Prepared for the Department of Housing and Construction.

Cardno Lawson Treloar (2009a) Storm Tide Hazard Study, Moreton Bay Regional Council. Prepared for Moreton Bay Regional Council. Report LJ8824/R2461v4.

Cardno Lawson Treloar (2009b) Storm Tide Hazard Study, Report Prepared for Redland Shire and Logan City Councils. Report LJ8824/R2504v2.

Cardno Lawson Treloar (2009c) Storm Tide Hazard Study Summary Report - Moreton Bay Regional Council.

Prepared for Moreton Bay Regional Council. Cardno Lawson Treloar Brisbane. Report LJ8824Rl.

Cardno Lawson Treloar (2009d) Storm Tide Hazard Study Summary Report - Redland Shire and Logan City Council's.

Prepared for Redland Shire and Logan City Council's. Cardno Lawson Treloar, Brisbane. Report LJ8824-R2.

Egbert, Eroveeva (2002) Efficient Inverse Modelling of Barotropic Ocean Tides. Journal of Atmospheric and Oceanic Technology, Vol. 19.

Foreman, (1977) Manual for Tidal Heights Analysis and Prediction. Pacific Marine Science Report 7710 , Institute of Ocean Sciences, Patricia Bay, B C, Canada.

Holland, (1980) An Analytical Model of the Wind and Pressure Profiles in Hurricanes. Monthly Weather Review, 108, pp 1212-1218.

Irish, Canizares., Grosskopf. and Williams. (2004) "The Effect of Hindcasted Waves on Coastal Storm Water Levels During the Blizzard of 2003".

Proceedings of the 8th International Workshop on Wave Hindcasting and Forecasting. Hawaii 14-19 November 2004.

Nguyen, Tanaka and Nagabayashi (2007) "Wave Setup at River and Inlet Entrances Due to an Extreme Event".

Proceedings of International Conference on Violent Flows. Kyushu University, Fukuoka, Japan 2007.

Tanaka. and Puzari. (1993) "Wave Set-up Measured in a River Mouth".

Proceedings of the 11th Australasian Conference on Coastal and Ocean Engineering. pp695-700 Engineers Australia, 1993.

Tanaka, Nagabayashi. and Yamauchi. (2000) Observation of Wave Set-up Height in a River Mouth. Proceedings of 27th International Conference on Coastal Engineering. Sydney, Australia. pp.3458-3471, 2000.

Taylor, Treloar and Collier. (2008) Lake Illawarra Entrance Studies - Flooding and Potential Climate Change Issues.

Proceedings of the 2008 NSW Coastal Conference. Wollongong, November 2008. 
Zhang, Reynolds, and Bates, (2006) Blended and Gridded High Resolution Global Sea Surface Wind Speed and Climatology from Multiple Satellites: 1987 - Present. American Meteorological Society 2006

Annual Meeting, Paper \#P2.23, Atlanta, GA, January 29 - February 2, 2006. 